\title{
Article
}

\section{Safety Leadership and Safety Knowledge-Attitude-Behaviour (KAB) in Malay- sia's Manufacturing SMEs: A Higher Order Two-Stage Approach of PLS-SEM.}

\author{
Syazwan Syah Zulkifly ${ }^{1, *}$, Mohd Rafee Baharudin² and Nor Halim Hasan ${ }^{3}$ \\ 1 School of Business Management, Universiti Utara Malaysia, 06010 Sintok, Kedah, Malaysia; \\ syazwan.syah@uum.edu.my \\ 2 Faculty of Medical and Health Science, Universiti Putra Malaysia, 43400 Serdang, Selangor, Malaysia; \\ mohdrafee@upm.edu.my \\ 3 Department of Occupational Safety and Health Malaysia, 62530 Putrajaya, Malaysia \\ * Correspondence: syazwan.syah@uum.edu.my
}

\begin{abstract}
Most of the accident cases at work are caused by unsafe behaviour. Scholars have thus extensively researched factors of safe behavior.Safety leadership is stated as the most effective factor in safety behaviour. Besides, safety knowledge and safety attitudes are also found to influence safety behaviour. The purpose of this paper is to investigate the nature of the relationship between safety leadership, safety knowledge, safety attitude, and safety behavior, which has been found to be limited or rare in previous research.A self-administered questionnaire was applied and was distributed randomly to 140 SME manufacturing workers and they were analysed using the structural equation modelling partial least squares (PLS-SEM). The results prove that safety leadership has a significant effect on safety knowledge, safety attitude, and safety behaviour, with safety knowledge and safety attitude mediating the safety leadership-safety behaviour relationship. Consequently, the results provide a more in-depth view of the relationship between safety leadership and safety knowledgeattitude-behaviour via adapting social-cognitive theory and social learning theory in solving safety issues in SME. This study also provides a starting point for researchers to better understand how effective safety leadership is provided by supervisors in terms of improving worker safety and safety knowledge-attitude-behaviour.
\end{abstract}

Keywords: safety knowledge; safety attitude; safety behaviour ; SME, Malaysia, manufacturing, PLS-SEM

\section{Introduction}

Industrial accidents have lately become a major issue in Malaysia, with the manufacturing sector having the largest number of recorded workplace accidents (Department of Occupational Safety and Health 2020). According to statistics, small and medium enterprises (SME) account for 80 percent to 90 percent of the cases (Aziz et al. 2015; Subramaniam et al. 2016). This demonstrated that Malaysian SMEs lack adequate safety management (Mohamed and Mohd Tamrin 2016; Surienty 2012). This predicament is the result of SMEs' constraints, particularly in terms of financial, knowledge, and staffing capacity (Surienty 2019), shortage of competent personnel, perceived difficulties in adopting $\mathrm{OSH}$, and low workplace accident risks (Md Deros et al. 2014). Furthermore, safety awareness among SME workers is found to be relatively low (Khoo, Surienty, and Daisy Kee 2011a).

The government of Malaysia, through the DOSH (Department of Occupational Safety and Health, Ministry of Human Resource Malaysia), has made tremendous efforts to address this issue by providing technical and compliance advice as well as conducting promotional activities aimed at small and medium-sized enterprises (SMEs) that are failing to improve their OSH levels and prevent accidents and diseases. Occupational Safety and Health Strategic Planning for SMEs has been developed to assist small businesses in 
complying with occupational-related laws and overcoming resource constraints (Zulkifly et al. 2018).

Despite, as previously stated, the constraints of SMEs, this study contends that SMEs should take advantage of their small size and flat structure to encourage employee safe behavior.Because of the simple organisational structure of SMEs, supervisors can exert control over their subordinates in terms of reducing unsafe behaviour. An appropriate and low-cost safety intervention can be implemented by utilising the role of the supervisor's safety leadership to influence safety behaviour (Khoo, Surienty, and Daisy Kee 2011a) and it has been proven that supervisory support is correlated to SME worker safety in Malaysia (Khoo, Surienty, and Daisy Kee 2011b).

Safety behaviour is determined to be one of the major determinants of a workplace accident, according to prior studies. Unsafe behaviour, such as ignoring safety procedures and failing to properly use personal protection equipment (Zakaria et al.,2012; Zalina Hussin et al.,2008; Sarok \& Susil,2012) has resulted in accidents in Malaysia's manufacturing sector, especially the SMEs. Moreover, Kidam et al. (2014) concluded that human factors and organisational failures were discovered to be among the safety difficulties that are present in manufacturing SMEs and have resulted in workplace accidents.Kidam et al. (2014) also discovered that human errors account for the majority of the causes of accidents in SME manufacturing.

Social Learning Theory (SLT), Bandura (1977) explained that humans learn from their interactions with others in a social context. Through observing the behaviours of others in their social context, they develop similar behaviours. Whereas, in Social Cognitive Theory (SCT), Bandura(1999) expanded the focus, based on SLT, on how humans manoeuvre cognitively on their social experiences and how these cognitions would furthermore influence their behaviours.

Meanwhile, a mediation safety climate model developed by Fugas et al. (2012) suggested a model for understanding compliance and preventive safety behaviors of employees called the social cognition mediation model. In detail, proximal situational elements (i.e., supervisor/coworker descriptive norms) influence worker safety behaviour, which is mediated by proximal person-related factors (i.e., attitude towards behaviour and perceived behavioural control). The descriptive norm refers to the practices that should be followed or avoided, while the injunctive norm refers to the rules that define the dos and don'ts of any behaviour (Harith and Mahmud 2020).

The knowledge and attitude of workers are required aspects for developing safety behaviours, according to the facts. Safety knowledge (Neal and Griffin 2006; Vinodkumar and Bhasi 2010) and safety attitude (M. S. Abdullah et al. 2016; Kao et al. 2019; Sugumaran et al. 2017) has been found to have a direct impact on safety behaviour. The research of the relationship between safety leadership and safety knowledge or attitude, on the other hand, is still new (K. H. Abdullah, Hashim, and Abd Aziz 2020). This is supported by Jiang \& Probst (2016), who claimed that no research has looked into the impact of supervisory leadership on safety awareness and participation. Also, Wu et al. (2015) determined that safety caring and coaching are two types of safety leadership that focus into subordinates' safety knowledge and conscientiousness, as well as achieving safety behaviour excellence. On one hand, workers who have regular interactions with their superiors about workplace safety issues are reported to have a positive safety attitude and are knowledgeable about executing tasks safely (Shen et al. 2017).

Based on the foregoing information, this study proposed a customised model for SME safety management that included safety leadership and safety KAB variables. Due to the limits that SMEs have, they must rely on internal resources (supervisors) to instil safety KAB in their employees. This concept is suggested as the most appropriate safety management model for SME manufacturing in Malaysia. 


\section{Literature Review}

\subsection{Safety Leadership and Safety Behaviour}

As mentioned earlier, worker safety behavior is the leading cause of occupational accidents and it has been demonstrated that good safety conduct predicts worker safety behavior. Previous extensive research has identified a significant relationship between leadership styles and security behavior based on several leadership theories. For example, Zhou and Jiang (2015) adopted leader-member exchange (LMX) theory and undertaken a research in a power supply company in China, to determine the connection between LMX and workers' safety behaviour. The results elucidated that LMX was positively related to safety behaviour, with a moderating effect of the safety climate.

Nonetheless, there have been studies that have discovered the impact of variables identifying safety leadership on safety behaviour. Lu and Yang (2010) for example, investigated the impact of safety leadership characteristics such as safety policy (transactional), safety motivation, and safety concern (transformational) on safety behaviour among Chinese container terminal workers. The two dimensions of safety behaviour were dubbed safety compliance and safety participation. The findings demonstrated that safety policy had a considerable impact on safety compliance but not on safety participation. F urthermore, both safety motivation and safety concern played a significant impact on safety behaviour.

Another example is Mullen and Kelloway (2011), conducted research with 241 young professionals and followed up with 491 senior workers who had been in the healthcare industry for a long time. The purpose of the study was to see if inconsistent safety-specific leadership style had an impact on safety behaviour. When compared to passive safetyspecific leadership, the results demonstrated that transformative safety-specific leadership had a stronger link to employee's safety behaviour. Workers' safety performance, particularly safety engagement behaviours, improves with an empowering leadership role. Similar to other countries, it is difficult to discover empirical evidences pertaining the relationship between safety leadership and safety behaviour in Malaysia. Adapting the measurement from Lu and Yang (2010); 210 SME manufacturing workers in Malaysia were studied by Zulkifly et al. (2017) for their safety leadership in terms of safety concern, safety policy, and safety motivation, as well as their effect on safety behaviour. The findings revealed that safety policy had the greatest impact on safety compliance, whereas safety motivation had a substantial impact on safety participation. Meanwhile, both dimensions of safety behaviour are influenced by safety concerns.

Scholars, on the other hand, have examined the impact of safety leadership factors on safety performance. For example, Wu et al. (2007) focused the impact of safety controlling, safety caring, and safety coaching, all of which reflect safety leadership, on the safety performance of four Taiwanese colleges. Path analysis showed that safety leadership predict safety performance. In Malaysia, a work form Lun and Wahab (2017) had investigated the influence of safety coaching, safety caring, and safety controlling of safety leadership on safety performance in the manufacturing sector, using a similar technique as well as intsrumentation. Beside that, Du and Sun (2012) tested the association between safety leadership variables, such as active management, safety motivation, and safety monitor; and safety climate in a study involving coal miners in China. Furthermore, transformational leadership includes active management and safety motivation, whereas transactional leadership includes safety monitoring. The results indicated that safety monitoring of safety leadership positively affects safety awareness of safety climate; safety commitment of safety climate has positively predicted by safety motivation of safety leadership, and active management of safety leadership has shown a significant impact on safety training of safety climate. In this study, the safety climate was used to reflect safety performance. 


\subsection{Safety Knowledge and Safety Behaviour}

Knowledge has the potential to influence behaviour explicitly or implicitly (Huang and Yang 2019). An employee's understanding of safe working methods, as well as proper safety training and teaching in terms of safety-related laws, rules, and standards, is referred to as safety knowledge (Burke et al. 2002; Griffin and Neal 2000; Hofmann, Jacobs, and Landy 2013; Jiang and Probst 2016b). As a corollary, safety knowledge is defined in this study as an employee's understanding of work-related safety issues, such as assessing work-related risks and safely completing activities to avoid accidents.

Safety knowledge is found to be essential in improving safety behaviour (Choudhry and Fang 2008). It can also influence the employees' adaption to safe work behaviour (Christian et al. 2009). Previously, Zohar (1980) has suggested that an individual's safety knowledge, particularly in terms of the perceived level of risk at work, promotes to safe working behaviour. Similarly, Mearns and Flin (1995) stated that safety knowledge includes how people perceive hazards, how they regulate those hazards, and how they share and communicate information about those hazards. Scholars have previously shown a significant linkage between safety knowledge and safety behaviour (Vinodkumar \& Bhasi, 2010; Murphy, 2008; Champbell et al., 2003; Griffin \& Neal, 2000; Neal et al., 2000). For example, Kao et al. (2019) performed a study and found that workers' safety knowledge predicts safety behaviour in the power plants in the southern United States. Moreover, Kao et al. (2019), who concluded in their study that workers who perceived their safety knowledge as high have a high likelihood of in engaging safety behaviour.Meanwhile, Vinodkumar \& Bhasi (2010) revealed in their study that workers' safety knowledge influenced their safety compliance behaviour in major hazard factories in Kerala, India.

Based on these works of literature, it could be concluded that safety knowledge is an essential factor in determining safety behaviour. Workers must be knowledgeable about occupational hazards in order to work safely and avoid accidents. (Fernández-Muñiz, Montes-Peón, and Vázquez-Ordás 2007). Probst and Brubaker (2001) stated that an employee with high safety knowledge would have higher safety behaviour. This statement similar to previous research's finding whereby individual knowlede of hazards the associated risks would make him/her behave safely when performing works (Mustafa, Aidil, and Harun 2015; Mustafa, Badlishah, and Abdul Razak 2017).

\subsection{Safety Attitude and Safety Behaviour}

Attitude is a judgment of an individual's sentiments towards something or someone (Gharibi et al. 2017). Attitude can have an impact on one's actions and reactions (Haynes et al., 2011). Safety attitude was characterised as an employee's predisposition to react favourably or negatively to workplace safety management procedures (Sari 1988). An attitude in aviation safety refers to a person's proclivity to make poor decisions (Joseph, Reddy, and Kashore Sharma 2013). As a basis, in this paper, a safety attitude is defined as workers' belief in the relevance of safety management or practises, as well as workplace behaviour, in preventing accidents.

Safety attitude is also found to affect safety behaviour by previous studies (M. S. Abdullah et al. 2016; Kao et al. 2019; Sugumaran et al. 2017). A research from Lim et al. (2016) to determine the impact of safety knowledge and attitude on food safety behaviour among kitchen employees in Semporna, Malaysia, researchers discovered that safety attitude had a substantial impact on safety behaviour. Warmerdam et al. (2018), discovered that workers' attitudes toward safety have a huge impact on their occupational driving behaviour among 911 drivers in 83 businesses with a lot of commute accidents. In China, Rau et al. (2018) looked into whether personality and safety attitude may predict elevator worker safety. The findings revealed that one's attitude toward safety had a considerable impact on one's safety behaviour. 
In Malaysia setting, Zulkifly et al. (2020) conducted a study determining the effect of safety knowledge and safety knowledge among solid waste general workers. The PLSSEM findings revealed that safety knowledge and attitude had a substantial impact on workers' safety behaviour. The degree of safety behaviour was similarly high, as measured by the mean value, and the variance in safety behaviour was 67 percent explained by safety knowledge and attitude.

\subsection{Conceptual Framework Development}

The majority of the safety leadership research was done outside of Malaysia. As a result, it is suggested that disparities in living and cultural values may result in differences in how leadership is exercised in Malaysia besides other countries (Zulkifly 2020). In the country with high power-distance (N. H. Abdullah et al. 2014; Zainuddin, Ismail, and Sapiei 2013), Malaysia's employees prefer their leader to impose clear guideline in performing tasks, and provide motivation and coaching towards workers(Shima et al. 2008). Furthermore, in Malaysia's organisational culture, reciprocity is a critical component of the leader-member interaction, where employees can return superiors' concern by following their leaders' directions (Tajaddini and Mujtaba 2009; Zulkifly 2020). Besides, previous scholars utilize safety controlling as one of the dimensions for safety leadership in Malaysia's setting (K. H. Abdullah and Aziz 2020; Chua and Wahab 2017). However, this paper proposed a similar dimension named as safety monitoring (Du and Sun 2012) as leaders' monitoring role was also found to predict safety participation behaviour. Besides safety monitoring, this research adapts safety concern as one dimension of safety leadership instead of safety caring because of the reciprocity element that is needed in Malaysia settings(Zulkifly 2020).

Humans can learn by their interactions with other individuals in a social context, according to Social Learning Theory (SLT). They develop similar behaviours through witnessing the actions of others(Bandura 1977). Whereas, in Social Cognitive Theory (SCT), Bandura(1999) widened the focus, based on SLT, on how humans manipulate their social experiences intellectualy and furthermore influence their behaviours. Meanwhile, a mediation safety climate model developed by Fugas et al. (2012) presented that the social cognition mediation model is a way to explain safety behaviours at work. In detail, safety behaviour of workers is influenced by proximal situational factors (i.e., supervisor/coworkers descriptive norms) and mediated by proximal person-related factors (i.e., attitude towards behaviour and perceived behavioural control). On the one hand, the model of safety management developed by Christian et al. (2009) proposed that safety knowledge would mediate the relationship of safety leadership and safety behaviour.This is proved by K. H. Abdullah \& Aziz (2020) who observed that safety knowledge and safety motivation had a mediating influence on the connection between safety leadership and safety behaviour in a study among laboratory students in Malaysia. Whereas, mediational model established by Fugas et al. (2012) illustrated that supervisors and co-workers' safety norms influence proactive safety behaviour, which is mediated by safety attitude and perceived behavioural control. Besides, a study using structural equation model (SEM) analysis proved that safety attitude mediated the relationship beyween safety leadership and safety behaviour among railway employees in China (Li et al. 2020).

Therefore, this study framework was developed and depicted in Figure 1. 


\section{Safety Leadership}

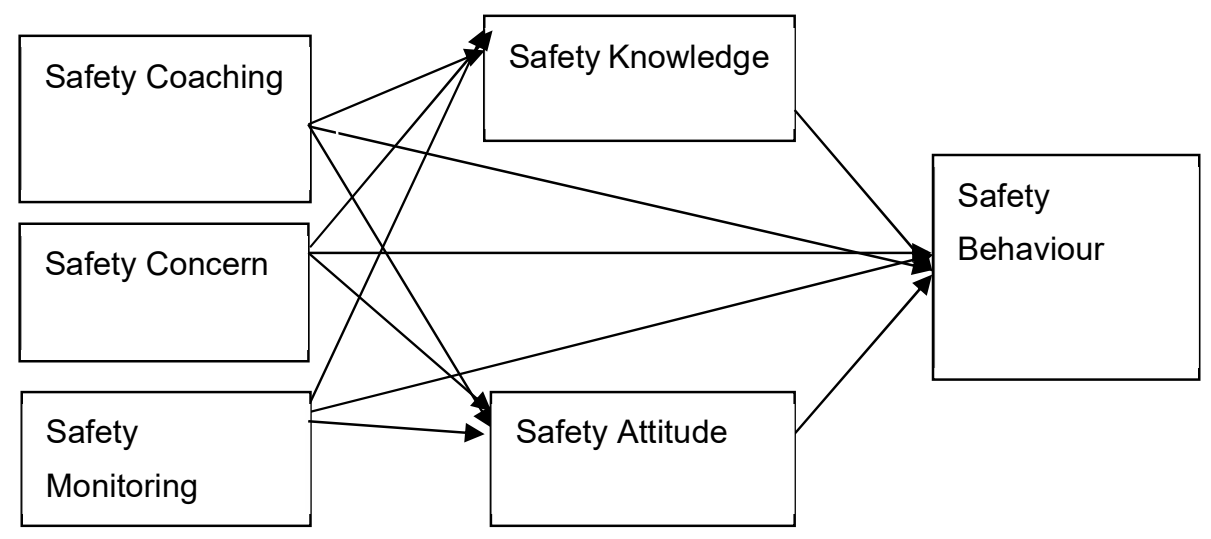

Figure 1. The Conceptual Framework adapted from Zulkifly (2020)

\section{Materials and Methods}

This is divided into several parts, providing the description of the research methodology.

\subsection{Research Design}

This is a quantitative cross-sectional design research, applying hypothesis testing analysis. Self-administred questionnaire has been used as the research instrument for data collection. SME (manufacturing) was chosen as the study setting and the northern region of Malaysia was chosen as the research area, specifically among the SMEs operating in the Northern Corridor Economic Region, as the NCER contribution is $31.6 \%$ of the GDP, higher than the national GDP (23.2\%). NCER forecasts a solid development led by manufacturing in 2021, which could fuel the development of SMEs (Northern Corridor Implementation Authority 2021). In terms of occupational safety and health, industrial accidents in the northern region of the state, including Perak, have been on the rise since 2010 and are expected to continue until 2020 (Department of Occupational Safety and Health 2020; Department of Occupational Safety and Health Malaysia 2016).

\subsection{Sampling Design and Procedure}

The data collection was undertaken at the SME (manufacturing) companies in the NCER. A total of 140 respondents who work as operators, and were selected randomly from SMEs registered with DOSH in a compliance support programme, answered the questionnaires.

The sample size was determined based on $\mathrm{G}^{*}$ Power as per depicted in Figure 2. 


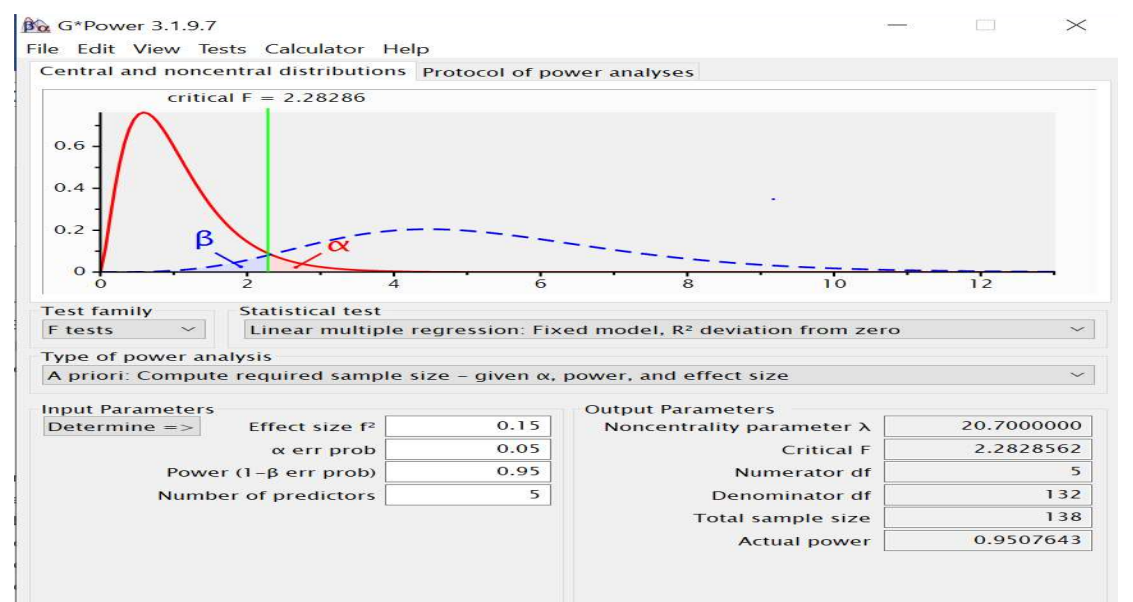

Figure 2. Sample Size Calculation by G*Power

A random table was used to select respondents from the population using systematic random sampling (MacNealy 1999).

\subsection{Research Instrument}

This study's measurement consists of reflective constructs scored on a five-point Likert scale (Likert 1932) ranging from 1 (strongly disagree) to 5 (strongly agree). A total of 5 items for safety coaching and safety concern with 6 items for safety monitoring were adapted and modified from T. C. Wu (2008). For safety behaviour, the 7 items were adapted from (Kao et al. 2019), whilst 5 items of safety knowledge (Vinodkumar and Bhasi 2010) and 4 items of safety attitude (Sawhney and Cigularov 2019) were adapted and modified to suite the study settings. The details of questionnaire's items are presented in Appendix A.

\subsection{Hypotheses Development}

Based on the conceptual framework established in 2.4, this research's hypotheses has been developed as follows:

$\mathrm{H}_{1}$ : Safety knowledge significantly mediates the effect of safety leadership on safety behaviour.

$\mathrm{H}_{2}$ : Safety attitude significantly mediates the effect of safety leadership on safety behaviour

\subsection{Data Analysis}

Partial-least-squares structural equation modelling (PLS-SEM) was utilised to examine the measurement and structural models for data analysis. When the goal of a study is to make predictions, it is more appropriate (F. Hair Jr et al. 2014) as compared to co-variance based structural equation modelling (CB-SEM).

In PLS-SEM, first, the meaurement model assessment was conducted to determine the validity and reliability of the instruments and framework. Furthermore, stuctural model was tested together with the hypthesis testing (Henseler, Ringle, and Sinkovics 2009; Ramayah et al. 2018). For the measurement model assesment, the lower-order construct (first -order) was used in the PLS-Algorithm analysis. Whereas, for measuring the structural model including hypotheses testing, the higher-order construct model were applied. Since this research utilising the two-stage approach, latent variable scores were taken to measure the structural model (Sarstedt et al. 2019). 


\section{Results and Discussions}

This section presented the overal results of the research.

\subsection{Respondent's Backgound}

Most of the respondents for this study are male, which are 95 people $(68 \%)$ of the total sample, and the remaining are female. In terms of their education level, $13.7 \%$ own LCE/SRP/PMR, 25\% MCE/SPM/SPMV , and HSC/STPM/certificate as was 30.3\%. On the other hand, most of the respondents work less than five years which are 84 persons (60 $\%$ ).

\subsection{Measurement Model Assessment}

\subsubsection{Reliability and Construct Validity}

The validity and reliability of the constructs were tested using internal consistency reliability, convergent validity, and discriminant validity for this study's measuring model (Henseler, Ringle, and Sarstedt 2014; Ramayah et al. 2018). The results in Table 1 show that all variables of the first order construct meet the construct validity criterion of CR > 0.7 and AVE >0.5 (F. Hair Jr et al. 2014; Ramayah et al. 2018).

Table 1. Reliability and Construct Validity

\begin{tabular}{lccc}
\hline & $\begin{array}{c}\text { Cronbach's } \\
\text { Alpha }\end{array}$ & $\begin{array}{c}\text { Composite } \\
\text { Reliability(CR) }\end{array}$ & $\begin{array}{c}\text { Average Variance } \\
\text { Extracted (AVE) }\end{array}$ \\
\hline Safety Attitude & 0.854 & 0.902 & 0.699 \\
Safety Behaviour & 0.929 & 0.943 & 0.703 \\
Safety Coaching & 0.884 & 0.914 & 0.682 \\
Safety Concern & 0.885 & 0.916 & 0.686 \\
Safety Knowledge & 0.923 & 0.942 & 0.765 \\
Safety Monitoring & 0.811 & 0.863 & 0.512 \\
\hline
\end{tabular}

\subsection{Discriminant Validity}

The constructs' discriminant validity was evaluated utilising the Heterotrait-Monotrait ratio (HTMT) approach as well as the Fornell-Larcker's criterion. The outcomes are shown in Tables 2 and 3.

Table 2. Fornell-Larcker's Results

\begin{tabular}{lllllll}
\hline & $\begin{array}{l}\text { Safety } \\
\text { Attitude }\end{array}$ & $\begin{array}{l}\text { Safety } \\
\text { Behaviour }\end{array}$ & $\begin{array}{l}\text { Safety } \\
\text { Coaching }\end{array}$ & $\begin{array}{l}\text { Safety } \\
\text { Concern }\end{array}$ & $\begin{array}{l}\text { Safety } \\
\text { Knowledge }\end{array}$ & $\begin{array}{l}\text { Safety } \\
\text { Monitoring }\end{array}$ \\
\hline Safety Attitude & $\mathbf{0 . 8 3 6}$ & & & & & \\
Safety Behaviour & 0.459 & $\mathbf{0 . 8 3 8}$ & & & & \\
Safety Coaching & 0.097 & 0.137 & $\mathbf{0 . 8 2 6}$ & & & \\
Safety Concern & 0.321 & 0.411 & 0.346 & $\mathbf{0 . 8 2 8}$ & & \\
Safety Knowledge & 0.288 & 0.381 & 0.437 & 0.378 & $\mathbf{0 . 8 7 5}$ & $\mathbf{0 . 7 1 6}$ \\
Safety Monitoring & 0.378 & 0.525 & 0.098 & 0.512 & 0.318 & \\
\hline
\end{tabular}


The Fornell-Larcker criterion analysis in Table 2 reveals that each construct's square root of the AVE exceeds the construct's highest correlation with any other construct in the model (Ab Hamid, Sami, and Mohmad Sidek 2017).

Table 4. HTMT Results

\begin{tabular}{llllll}
\hline Safety & Safety & Safety & Safety & Safety & Safety \\
Attitude & Behaviour & Coaching & Concern & Knowledge & Monitoring \\
\hline
\end{tabular}

Safety Attitude

Safety Behaviour

0.503

Safety Coaching

0.117

0.145

Safety Concern

0.367

0.451

Safety Knowledge

0.324

0.409

0.387

Safety Monitoring

0.431

0.582

0.464

0.415

Additionally, the heterotrait-monotrait ratio (HTMT) calculations presented in Table 3 indicates the HTMT values for all constructs are less than the conservative threshold value of 0.85(Ab Hamid, Sami, and Mohmad Sidek 2017; Franke and Sarstedt 2019). The measurement model of the first-order construct is presented in Appendix B- Figure A1.

\subsection{Structural Model Assessment (Hypothesis Testing)}

Safety coaching, safety concern, and safety monitoring were conceptualised as second-order constructs with formative indications in this study, using the reflective-formative type II framework (Becker, Klein, and Wetzels 2012). The second-order constructs were assessed using the embedded two-stages approach as proposed by (Sarstedt et al. 2019). First, the structural model's predictive power was assessed using the endogenous construct's coefficient of determination (R2 values) (Hair et al. 2017; Henseler, Ringle, and Sinkovics 2009; Ringle, Da Silva, and Bido 2014). The $R^{2}$ values for safety attitude were 0.149 , indicating a modest predictive potential, but the $\mathrm{R}^{2}$ values for safety knowledge (0.232) and safety behaviour (0.361) were significant (Cohen et al. 1998). On the other hand, the predictor constructs can be assessed by using the effect size of Cohen , $f^{2}$ (Glass and Cohen 2012). The findings revealed that safety leadership had a medium effect size on safety attitude (0.175) and safety knowledge (0.302), but a modest effect size on safety behaviour (0.130). Furthermore, the impact of safety knowledge (0.021) and safety attitude (0.109) on safety behaviour was minimal.

This study also explored the relationship between safety leadership, safety knowledge, safety attitude, and safety behaviour. Furthermore, the mediating role of safety knowledge and safety attitude was investigated in this study. A 1000 re-sampled bootstrapping was performed, with the results shown in Table 5 . 
Table 5. Hypothesis Testing Results

\begin{tabular}{lcccc}
\hline & Beta- & & & \\
Hypothesis & & T Statistics & P Value & Results \\
& Value & & & Supported \\
\hline Safety Leadership $->$ Safety Attitude $->$ Safety Behaviour & 0.111 & 4.470 & 0.000 & Supported \\
Safety Leadership $->$ Safety Knoweldge $->$ Safety Behaviour & 0.064 & 2.311 & 0.021 & \\
\hline
\end{tabular}

According to the findings in Table 5, safety knowledge mediated the association between safety leadership and safety behaviour. $(\beta=0.064, \mathrm{p}<0.05)$. This result is supported by K. H. Abdullah \& Aziz (2020) discovered that the link between safety leadership and safety behaviour among Malaysian laboratory students was mediated by safety knowledge and safety motivation. Similarly, this study deterimined the mediating effect of safety attitude on the relationship between safety leadership and safety behaviour $(\beta=$ 0.111, $\mathrm{p}<0.05)$. This result corroborated the findings of Fugas et al. (2012) and also Li et al. (2020). The structural model of the second-order construct is presented in Appendix BFigure A2.

Based on the results also, it could be stated that all hypotheses of this study are accepted.

\section{Conclusions}

Safety behavior has been identified as the primary cause of workplace mishaps, including SMEs in Malaysia (Khoo, Surienty, and Selamat 2016; Zulkifly et al. 2018), and this study suggests that supervisory safety leadership in terms of safety coaching, safety concern, and safety monitoring could predict safety performance in terms of behavior., this study established a higher-order research framework of safety leadership and safety behaviour relationships which is mediated by safety knowledge and attitude. The development of this framework was based on previous literature (K. H. Abdullah and Aziz 2020; Fugas, Silva, and Meliá 2012) as well as theories, namely SLT and SCT (Bandura 1977, 1999). Safety leadership by supervisors has a direct and significant influence on safety behaviour, according to the results. Furthermore, the data indicates that safety knowledge and attitude are important in mediating the relationship between safety leadership and safety behaviour. Overall, this study discovered that supervisor safety leadership has a significant influence on worker safety knowledge and attitudes. Overall, the present research makes a variety of contributions. To begin with, the study supports the use of social learning theory and social cognitive theory to investigate the link between safety leadership, safety knowledge, safety attitude, and safety behaviour. In addition, this research helps with the expansion of the safety behaviour model (Christian et al. 2009) through the addition of the mediating role of safety attitude (distal personal factor) towards the relationship between safety leadership (distal situational factor) and safety behaviour. Moreover, the results support the safety climate model (Fugas, Silva, and Meliá 2012) while suggesting that supervisory safety leadership positions be incorporated as a component of descriptive and injunctive safety norms. This study also filled a gap in prior research, focusing on the mediating function of safety attitude in the link between safety leadership and safety behaviour, which is still a new concept. Furthermore, the findings of this research add to the little empirical evidence on the mediating function of safety knowledge in the effect between safety leadership and safety behaviour (K. H. Abdullah and Aziz 2020). The overall findings of the current study, on the other hand, provide a 
clearer understanding of how supervisors' safety leadership affects worker safety behaviour, as mediated by safety knowledge and attitude. This study also provides useful data and information for SMEs' management in their efforts to improve safe behavior.Furthermore, the trustworthy and valid study methodology might serve as a starting point for the government in developing targeted occupational safety and health intervention programmes for SMEs, in order to improve their safety performance from the angle of safety knowledge and safety attitude of workers.

Author Contributions: Conceptualisation, S.S.Z. and N.H.H.; methodology, S.S.Z and M.R.B.; software, N.H.H.; validation S.S.Z., M.R.B.; formal analysis, S.S.Z., M.R.B.; investigation, S.S.Z. and N.H.H..; resources, S.S.Z. and N.H.H.; data curation, S.S.Z. and N.H.H.; writing-original draft preparation, S.S.Z.; writing - review and editing, S.S.Z, N.H.H and M.R.B.; visualization, X.X.; supervision, M.R.B.; project administration, N.H.H. All authors have read and agreed to the published version of the manuscript.

Funding: This research received no external funding

Acknowledgments: We would like to thank all the respondents of this study. We also indebted to the Department of Occupational Safety and Health (DOSH)Malaysia for their willingness to assist and collaborate for data collection of this study.

Conflicts of Interest: The authors declare no conflict of interest.

\section{Appendix A}

The items of research's instrument.

\section{Safety Coaching (SCh)}

Supervisors demonstrate how to deal with job risks.

The supervisor demonstrates how to observe safety regulations through example.

The supervisor assists workers in identifying potential risks in the workplace.

The supervisor goes into great depth regarding the dangers that exist in the job.

Workers are included in the decision-making process of safety

\section{Safety Concern (SCn)}

The supervisor emphasises the need of wearing personal protection equipment.

The supervisor is constantly interested in preventing risks.

Supervisors are constantly concerned about improving safety.

The supervisor always works with the management to solve safety problems.

Supervisors are constantly concerned about worker safety.

\section{Safety Monitoring (SMn)}

Supervisor firmly instructs employees to achieve safety targets.

Supervisor evaluates workers' safety performance on a regular basis

Supervisor and they enforce safety rules.

Employees must follow safe work practises, according to the supervisor.

Supervisor always asks wokers to improve safety behaviour.

Supervisor routinely monitors the safety performance of employees.

\section{Safety Knowledge (SK)}

I know how to perform my job in a safe manner.

I know how to use safety equipment.

I know how to improve workplace safety conditions.

I know how to reduce the risk of accidents and incidents in the workplace.

I am able to identify hazards/danger associated to my work. 


\section{Safety Attitude (SA)}

I believe that it is important to work in safe manner.

I believe safety is more important than finishing works quickly.

I feel that it is important to follow SOP even it may take longer time to finish works.

I feel that it is important to wear PPE even it may cause inconvenience in doing work.

\section{$\underline{\text { Safety Behaviour (SB) }}$}

I follow all safety regulations when I work.

When I work, I put on personal protection equipment.

I improve hazardous situations that accidents do not occur.

During the workday, I encourage my coworkers to follow safety regulations.

If there are any situations that might lead to an accident, I notify my supervisors.

Before I start working, I check the workplace for safety hazards.

I notify my supervisors whenever my co-wokers commit unsafe behaviour.

\section{Appendix B}

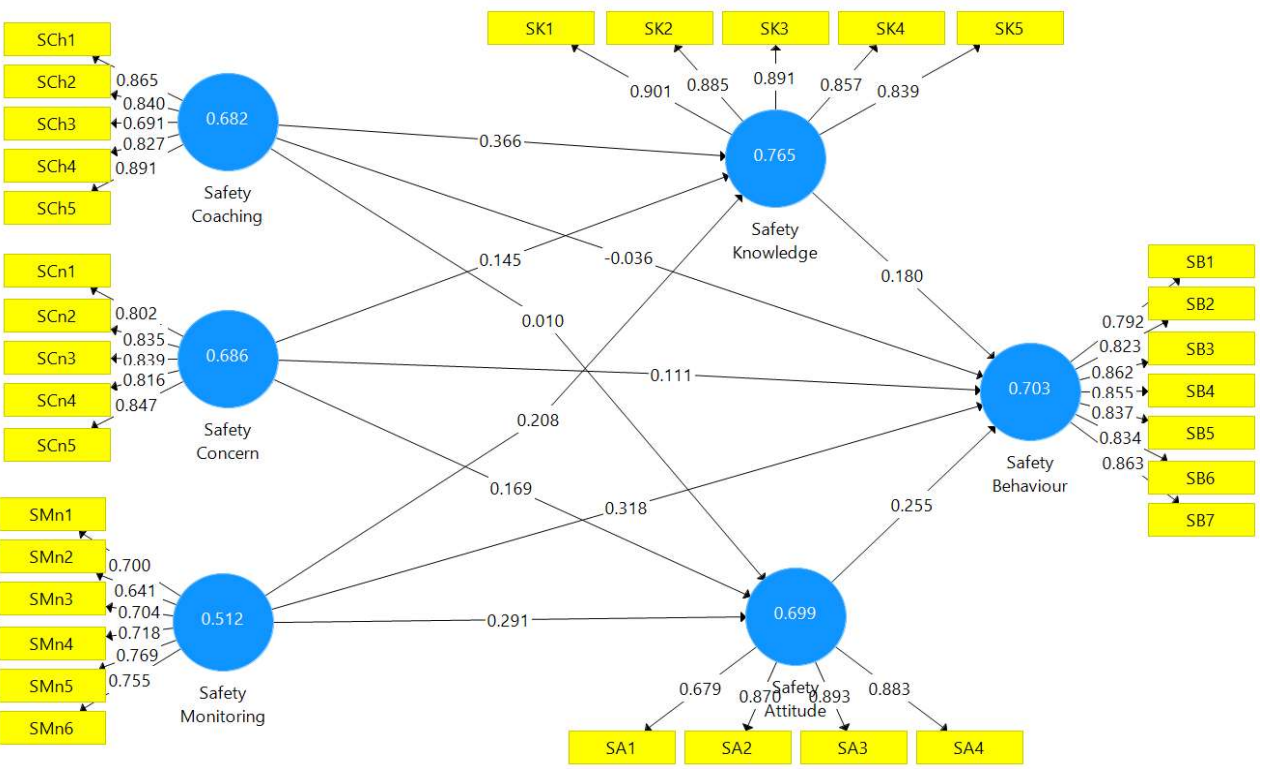

Figure A1. Measurement Model for First Oder Construct 


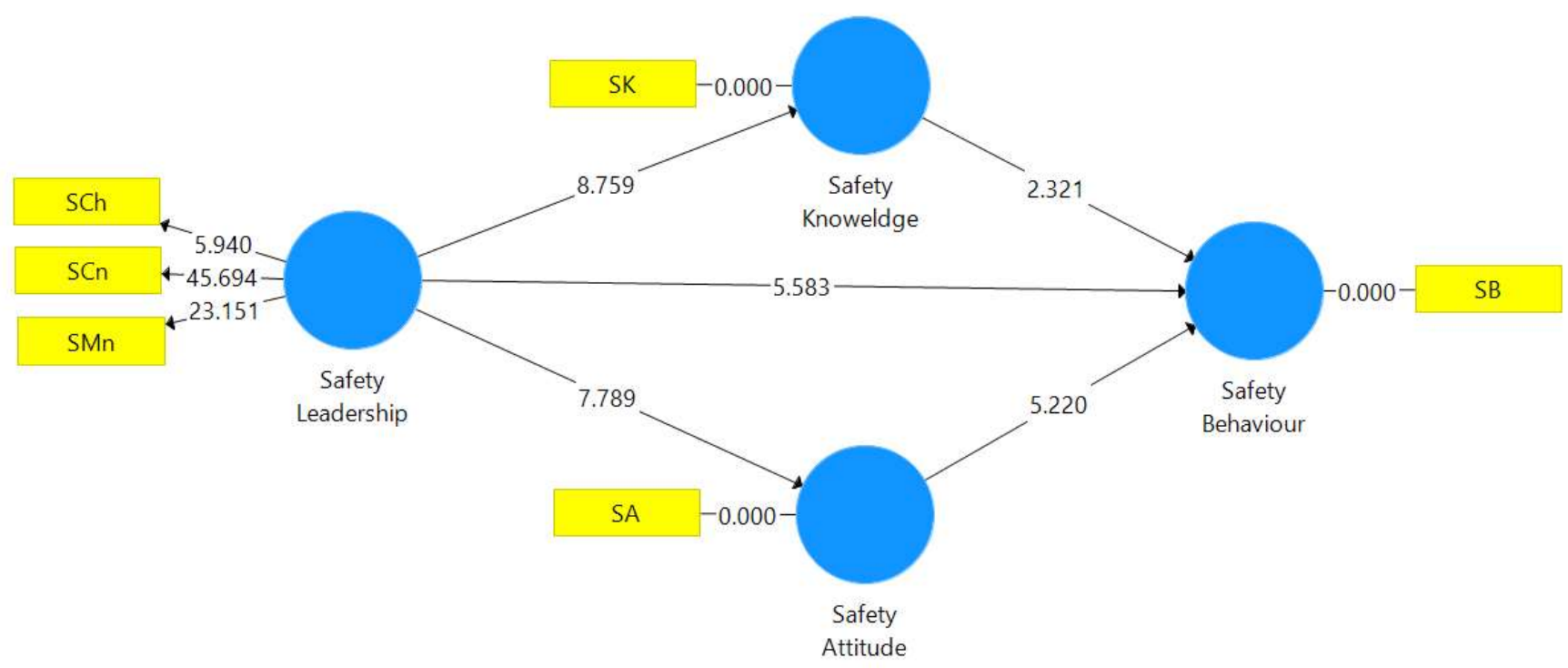

Figure A2. Structural Model (Second-Order Construct)

\section{References}

Ab Hamid, M. R., W. Sami, and M. H. Mohmad Sidek. 2017. “Discriminant Validity Assessment: Use of Fornell \& Larcker Criterion versus HTMT Criterion." In Journal of Physics: Conference Series,.

Abdullah, Khairul Hafezad, and Fadzli Shah Abd Aziz. 2020. "Safety Behavior in the Laboratory among University Students." Journal of Behavioral Science 15(3): 51-65.

Abdullah, Khairul Hafezad, Mohd Nazri Hashim, and ShahFadzli Abd Aziz. 2020. "A 39 Years ( 1980-2019) Bibliometric Analysis of Safety Leadership Research." Test Engineering \& Management 83: 4526-42.

Abdullah, Muhammad Safizal, Yusuf Hj Othman, Abdullah Osman, and Shahrul Nizam Salahudin. 2016. "Safety Culture Behaviour in Electronics Manufacturing Sector (EMS) in Malaysia: The Case of Flextronics." Procedia Economics and Finance 35(March): 454-61. http://dx.doi.org/10.1016/S2212-5671(16)00056-3.

Abdullah, Nawal Hanim, Hamimah Hassan, Mass Hareeza Ali, and Muhammad Shahrim Ab. Karim. 2014. “Cultural Values (Power Distance) Impact on the Stakeholders' Engagement in Organizing the Monsoon Cup International Sailing Event." Procedia Social and Behavioral Sciences 144: 118-26. http://dx.doi.org/10.1016/j.sbspro.2014.07.280.

Aziz, Amirrudin Abdul et al. 2015. "A Preliminary Study on Accident Rate in the Workplace through Occupational Safety and Health Management in Electricity Service." Quest Journals Journal of Research in Business and Management 2(12): 9-15. www.questjournals.org (May 4, 2017).

Bandura, Albert. 1977. Prentice-Hall Bandura - Social Learning Theory. Englewood Cliffs, NJ: Prentice-Hall.

- - - 1999. "Social Cognitive Theory: An Agentic Perspective." Asian Journal of Social Psychology.

Becker, Jan Michael, Kristina Klein, and Martin Wetzels. 2012. "Hierarchical Latent Variable Models in PLS-SEM: Guidelines for Using Reflective-Formative Type Models." Long Range Planning 45(5-6): 359-94. http://dx.doi.org/10.1016/j.lrp.2012.10.001.

Bowonder, B. 1987. "Industrial Hazard Management An Analysis of the Bhopal Accident." Project Appraisal 2(3): 157-67.

Burke, Michael J., Ann Sue Sarpy, Paul E. Tesluk, and Kristin Smith-Crowe. 2002. “General Safety Performance: A Test of a Grounded Theoretical Model." Personnel Psychology 55(2): 429-57.

Choudhry, Rafiq M., and Dongping Fang. 2008. "Why Operatives Engage in Unsafe Work Behavior: Investigating Factors on Construction Sites." Safety Science 46: 566-84. www.elsevier.com/locate/ssci (May 5, 2017). 
Christian, Michael S, Jill C Bradley, J Craig Wallace, and Michael J Burke. 2009. “Workplace Safety: A Meta-Analysis of the Roles of Person and Situation Factors." The Journal of applied psychology 94(5): 1103-27.

Chua, Jing Lun, and Shah Rollah Abdul Wahab. 2017. "The Effects of Safety Leadership on Safety Performance in Malaysia ." Saudi Journal of Business and Management Studies 2(12-18).

Cohen, Lawrence H., Kathleen Cimbolic, Stephen R. Armeli, and Tanya R. Hettler. 1998. “Quantitative Assessment of Thriving." Journal of Social Issues 54(2): 323-35.

Department of Occupational Safety and Health. 2020. "Industrial Accident Statistics." www.dosh.gov.my.

Department of Occupational Safety and Health Malaysia. 2016. “Keselamatan Dan Kesihatan Pekerjaan Untuk Kesejahteraan Kita Laporan Tahunan 2016." : 5-10.

Du, Xuesheng, and Wenbiao Sun. 2012. "Research on the Relationship between Safety Leadership and Safety Climate in Coalmines." Procedia Engineering 45: 214-19.

F. Hair Jr, Joe, Marko Sarstedt, Lucas Hopkins, and Volker G. Kuppelwieser. 2014. “Partial Least Squares Structural Equation Modeling (PLS-SEM)." European Business Review 26(2): 106-21.

Fernández-Muñiz, Beatriz, José Manuel Montes-Peón, and Camilo José Vázquez-Ordás. 2007. “Safety Culture: Analysis of the Causal Relationships between Its Key Dimensions." Journal of Safety Research 38(6): 627-41.

Franke, George, and Marko Sarstedt. 2019. “Heuristics versus Statistics in Discriminant Validity Testing: A Comparison of Four Procedures." Internet Research 29(3): 430-47.

Fugas, Carla S., Sílvia A. Silva, and José L. Meliá. 2012. “Another Look at Safety Climate and Safety Behavior: Deepening the Cognitive and Social Mediator Mechanisms." Accident Analysis and Prevention 45(2012): 468-77. http://dx.doi.org/10.1016/j.aap.2011.08.013.

Gharibi, Vahid et al. 2017. “The Relationship between Workers' Attitude towards Safety and Occupational Accidents Experience.” International Journal of Occupational Hygiene 8: 145-50. http://ijoh.tums.ac.ir.

Glass, G.V., and Jacob Cohen. 2012. “Using Effect Size-or Why the P Value Is Not Enough.” Journal of Graduate Medical Education (September): 279-82.

Griffin, Mark A., and Andrew Neal. 2000. “Perceptions of Safety at Work: A Framework for Linking Safety Climate to Safety Performance, Knowledge, and Motivation." Journal of Occupational Health Psychology.

Gyekye, Seth Ayim. 2010. “Occupational Safety Management: The Role of Causal Attribution.” International Journal of Psychology 45(6): 405-16.

Hair, J. F., G. T. M. Hult, C. M. Ringle, and M. Sarstedt. 2017. Sage A Primer on Partial Least Squares Structural Equation Modeling (PLSSEM). 2nd Revise. US.

Harith, Siti Hawa, and Norashikin Mahmud. 2020. “The Relationship between Norms and Risky Driving Behavior: A Systematic Review." Iranian Journal of Public Health 49(2): 211-20.

Henseler, Jörg, Christian M. Ringle, and Marko Sarstedt. 2014. “A New Criterion for Assessing Discriminant Validity in VarianceBased Structural Equation Modeling." Journal of the Academy of Marketing Science 43(1): 115-35.

Henseler, Jörg, Christian M. Ringle, and Rudolf R. Sinkovics. 2009. “The Use of Partial Least Squares Path Modeling in International Marketing." Advances in International Marketing 20(January): 277-319.

Hofmann, David A., Rick Jacobs, and Frank Landy. 2013. “High Reliability Process Industries: Individual, Micro, and Macro Organizational Influences on Safety Performance." Journal of Safety Research 26(3): 131-49.

Huang, Ying Hua, and Tzung Ru Yang. 2019. "Exploring On-Site Safety Knowledge Transfer in the Construction Industry." Sustainability (Switzerland) 11(22): 1-16.

Jiang, Lixin, and Tahira M. Probst. 2016a. “Transformational and Passive Leadership as Cross-Level Moderators of the Relationships between Safety Knowledge, Safety Motivation, and Safety Participation." Journal of Safety Research 57: 27-32. 
- - - 2016b. "Transformational and Passive Leadership as Cross-Level Moderators of the Relationships between Safety Knowledge, Safety Motivation, and Safety Participation." Journal of Safety Research 57: 27-32. http://dx.doi.org/10.1016/j.jsr.2016.03.002.

Joseph, Catherine, Suhasini Reddy, and Kanwal Kashore Sharma. 2013. “Locus of Control, Safety Attitudes and Involvement in Hazardous Events in Indian Army Aviators." Aviation Psychology and Applied Human Factors 3(1): 9-18.

Kao, Kuo Yang, Christiane Spitzmueller, Konstantin Cigularov, and Candice L. Thomas. 2019. “Linking Safety Knowledge to Safety Behaviours: A Moderated Mediation of Supervisor and Worker Safety Attitudes." European Journal of Work and Organizational Psychology 28(2): 206-20.

Khoo, Teng Hong, Lilis Surienty, and Mui Hung Daisy Kee. 2011a. “Occupational Safety and Health ( OSH ) in Malaysian Small and Medium Enterprise and Effective Safety Management." International Journal of Business and Technopreneurship 1(November): 321-38.

- - - 2011b. "Safety Management Practices and Safety Behaviour : A Preliminary Investigation in Malaysian Small and Medium Enterprises in Northern Corridor Economic Region ( NCER )." In Journal Occupational Safety E Health, , 1-11.

Khoo, Teng Hong, Lilis Surienty, and Mohd Nasir Selamat. 2016. "Safety Training and Safety Behaviour in the Malaysian SME." Journal of Occupational Safety and Health 13(2): 55-62.

Kidam, Kamarizan, Zainazrin Zainal, Zulkifly Sulaiman, and Mimi Haryani. 2014. "Statistical Analysis of Metalworking Accidents within Small and Medium Enterprises ( SMEs ) in Malaysia." In 3rd Scientific Conference on Occupational Safety and Health- SciCosh 2014, Kuala Lumpur: NIOSH Malaysia.

Li, Mengjie, Huaiyuan Zhai, Junjie Zhang, and Xiangcheng Meng. 2020. "Research on the Relationship between Safety Leadership, Safety Attitude and Safety Citizenship Behavior of Railway Employees." International Journal of Environmental Research and Public Health 17(6): 1-17.

Likert, R. 1932. "A Technique for the Measurement of Attitudes." Archives of Psychology.

Lim, Tee Ping et al. 2016. "A Structural Modeling on Food Safety Knowledge, Attitude, and Behaviour among Bum Bum Island Community of Semporna, Sabah." Food Control 60: 241-46.

Lu, Chin Shan, and Chung Shan Yang. 2010. "Safety Leadership and Safety Behavior in Container Terminal Operations." Safety Science.

MacNealy, M.S. 1999. Strategies for Empirical Research in Writing. New York: Longman.

Md Deros, Baba, Ahmad Rasdan Ismail, Jaharah A. Ghani, and Mohd Yusri Mohd Yusof. 2014. “Conformity to Occupational Safety and Health Regulations in Malaysian Small and Medium Enterprises." American Journal of Applied Sciences 11(3): 499-504.

Mohamed, Noradila, and Shamsul Bahri Mohd Tamrin. 2016. “Relationship between Safety Climate Perception and Safety and Health Management System with Occupational Accident at Small Medium Industries in Selangor." Journal Occupational Safety $\mathcal{E}$ Health 13(2).

Mustafa, Munauwar, Shahrizal Badlishah, and Ummey Abdul Razak. 2017. "Hubungan Di Antara Komitmen Keselamatan Dan Prestasi Keselamatan Pemandu-Pemandu." Journal of Global Business and Social Entrepreneurship 3(9): 12-24.

Mustafa, Munauwar Bin, Muhamad Aidil, and Bin Harun. 2015. “Hubungan Antara Iklim Keselamatan Dengan Prestasi Keselamatan Pekerjaan Di ILJTM Lembah Klang." SkillsMalaysia Journal 1(1): 107-15.

Neal, Andrew, and Mark A. Griffin. 2006. “A Study of the Lagged Relationships among Safety Climate, Safety Motivation, Safety Behavior, and Accidents at the Individual and Group Levels." Journal of Applied Psychology.

Northern Corridor Implementation Authority. 2021. Northern Corridor Implementation Authority Northern Corridor Economic Region (NCER) Strategic Development Plan (2021-2025).

Probst, T. M., and T. L. Brubaker. 2001. “The Effects of Job Insecurity on Employee Safety Outcomes: Cross-Sectional and Longitudinal Explorations." Journal of occupational health psychology 6(2): 139-59.

Ramayah, T et al. 2018. Practical Assessment, Research and Evaluation Partial Least Squares Structural Equation Modeling (PLS-SEM) 
Using SmartPLS 3.0: An Updated Guide and Practical Guide to Statistical Analysis.

Rau, Pei Luen Patrick et al. 2018. "Personality Factors and Safety Attitudes Predict Safety Behaviour and Accidents in Elevator Workers." International Journal of Occupational Safety and Ergonomics 0(0): 1-21. https://doi.org/10.1080/10803548.2018.1493259.

Ringle, Christian M., Dirceu Da Silva, and Diógenes De Souza Bido. 2014. “Structural Equation Model with Smartpls." Revista Brasileira de Marketing 13(2): 56-73.

Sari, J. 1988. "Successful Accident Prevention. An Intervention Study in the Nordic Countries." Scand .J .Work Environ. Health 14 1: $121-23$.

Sarstedt, Marko et al. 2019. "How to Specify, Estimate, and Validate Higher-Order Constructs in PLS-SEM." Australasian Marketing Journal 27(3): 197-211.

Sawhney, Gargi, and Konstantin P. Cigularov. 2019. "Examining Attitudes, Norms, and Control toward Safety Behaviors as Mediators in the Leadership-Safety Motivation Relationship." Journal of Business and Psychology 34(2): 237-56.

Shen, Yuzhong et al. 2017. “The Impact of Transformational Leadership on Safety Climate and Individual Safety Behavior on Construction Sites." International Journal of Environmental Research and Public Health 14(1): 1-17.

Shima, Nazatul et al. 2008. "Malaysian Employees' Preference Of Their Managers Leadership Style." International Review of Business Research Papers 4(5): 97-108. http://citeseerx.ist.psu.edu/viewdoc/download?doi=10.1.1.505.2901\&rep=rep1\&type=pdf.

Subramaniam, Chandrakantan et al. 2016. "Safety Management Practices and Safety Compliance in Small Medium Enterprises." Asia-Pacific Journal of Business Administration.

Sugumaran, Bavani, Muhammad Safizal Abdullah, Arman Hadi, and Abdul Manaf. 2017. "Safety Compliance Behaviour in Manufacturing Industry: A Malaysian Perspective." Saudi Journal of Humanities and Social Sciences 2(1): 66-73.

Surienty, Lilis. 2012. “Management Practices and OSH Implementation in SMEs in Malaysia." Management (February): 1-13.

- - - 2019. “OSH Implementation in SMEs in Malaysia: The Role of Management Practices and Legislation." Advances in Intelligent Systems and Computing 819(November 2018): 650-71.

Tajaddini, Reza, and Bahaudin G Mujtaba. 2009. "Stress Perceptions and Leadership Orientation of Malaysians: Exploring Their Similarities and Differences with Americans." Chinese Business Review 08(08): 26-42.

Vinodkumar, M N, and M Bhasi. 2010. “Safety Management Practices and Safety Behaviour: Assessing the Mediating Role of Safety Knowledge and Motivation." Accident Analysis and Prevention 42: 2082-93. http://ac.els-cdn.com/S0001457510001855/1-s2.0S0001457510001855-main.pdf?_tid=6bc904fa-31ac-11e7-936700000aacb360\&acdnat=1494000407_e6fe8d067fb137c63478186db2797ba8 (May 6, 2017).

Warmerdam, Amanda et al. 2018. “High Performance Workplace Systems' Influence on Safety Attitudes and Occupational Driver Behaviour." Safety Science 106(March): 146-53.

Wu, Chunlin, Dongping Fang, and Nan Li. 2015. "Roles of Owners' Leadership in Construction Safety: The Case of High-Speed Railway Construction Projects in China." International Journal of Project Management 33(8): 1665-79.

Wu, Tsung Chih. 2008. "Safety Leadership in the Teaching Laboratories of Electrical and Electronic Engineering Departments at Taiwanese Universities." Journal of Safety Research 39(6): 599-607. http://dx.doi.org/10.1016/j.jsr.2008.10.003.

Zainuddin, Suria, Kamisah Ismail, and Sharoja Sapiei. 2013. “The Influence of Cultural Value in Malaysian Firms: A Research Note.” Journal of Business and Economics 4(12): 1276-85. http://www.academicstar.us.

Zhou, Fan, and Chunping Jiang. 2015. “Leader-Member Exchange and Employees' Safety Behavior: The Moderating Effect of Safety Climate." Procedia Manufacturing.

Zulkifly, Syazwan Syah et al. 2020. “Assessing the Level of Safety Knowledge-Attitude-Behaviour (Safety KAB): A Case Study in a Public Cleansing Firm." Journal of Safety, Health and Ergonomics 2(1): 1-7.

- - . 2020. "Safety Leadership and Its Effect on Safety Knowledge-Attitude-Behaviour ( KAB ) of Malaysia Manufacturing 
Workers." International Journal of Solid State Technology 63(3): 218-29.

Zulkifly, Syazwan Syah, Chandrakantan Subramaniam, and Nor Halim Hasan. 2017. “Examining the Influence of Safety Leadership towards Safety Behaviour in SME Manufacturing." Occupational Safety and Health 14(1): 17-23.

Zulkifly, Syazwan Syah, Izani Mohd Zain, Nor Halim Hasan, and Mohd Rafee Baharudin. 2018. “Workplace Safety Improvement in Sme Manufacturing: A Government Intervention." International Journal of Science and Technology 4(2): 29-39. 